\title{
Algunas consideraciones acerca de las enfermedades transmiti- das por alimentos
}

\section{J. Selva Andina Res. Soc. 2015; 6(1):1.}

Las enfermedades transmitidas por alimentos - ETA (definidas como cualquier síndrome-conjunto de signos y síntomasoriginado por la ingestión de productos alimenticios o ingredientes, especias, bebidas o agua que contienen agentes etiológicos en cantidades suficientes para afectar la salud del consumidor a nivel individual o en grupos de población) constituyen un grave problema mundial en materia de salud pública.

Los alimentos insalubres o contaminados enferman cada año al menos a dos mil millones de personas, y pueden causar la muerte. A pesar de que algunos países han hecho grandes adelantos para controlar la carga de morbilidad asociada a los alimentos, a nivel mundial ese número está creciendo. Las amenazas de contaminación que afectan a los alimentos que se consumen pueden provenir de los lugares donde crecen los cultivos o se crían los animales productores y ascienden a lo largo de la cadena hasta llegar a la manera en que se los elabora, sumado al hecho de que muchas poblaciones carecen de agua potable para su consumo lo cual representa un alto factor de riesgo para la presentación de enfermedades gastroentéricas.

Resulta muy difícil estimar la incidencia real de casos por esta patología ya que los afectados, de acuerdo a la mayor o menor severidad del cuadro clínico, no siempre consultan a los servicios de salud y por lo tanto no quedan registrados y notificados a las autoridades sanitarias, situación que se presenta tanto en países desarrollados y aún más, en los países en desarrollo.

El problema de las ETA no sólo se relaciona al daño físico que causan, si bien en algunas ocasiones puede ser fatal, sino también al impacto socioeconómico de carácter negativo asociado implícitamente, ya que se ven afectados tanto la persona enferma como el sector de la producción alimenticia y los servicios de salud público o privado.

La carga de morbilidad de las enfermedades transmitidas por los alimentos es muy significativa. Una mejor organización y comunicación entre las autoridades sanitarias y con los consumidores permitiría reducir significativamente esa carga. El fortalecimiento de los sistemas nacionales de inocuidad de los alimentos encargados de la fiscalización a lo largo de toda la cadena de producción alimentaria, el accionar responsable de productores y elaboradores y la participación activa de los consumidores (capacitados en la adecuada preparación higiénica de los alimentos) permitiría gestionar de forma más eficaz el suministro de productos alimenticios inocuos para la población.

Claudio Marcelo Zotta Instituto Nacional de Epidemiología "Dr. Juan H. Jara" (INE) Administración Nacional de Laboratorios e Institutos de Salud “Carlos G. Malbrán” (ANLIS) Ministerio de Salud de la Nación Argentina Mar del Plata, Argentina. 0223-4733449. marcelozotta@hotmail.com

2015. Journal of the Selva Andina Research Society. Bolivia. Todos los derechos reservados 